\title{
A Novel Approach for Operating Speed Continuous Predication Based on Alignment Space Comprehensive Index
}

\author{
Ying Yan, ${ }^{1}$ Gengping Li, ${ }^{1}$ Jinjun Tang, ${ }^{2}$ and Zhongyin Guo ${ }^{3}$ \\ ${ }^{1}$ School of Automobile, Chang'an University, Xian, China \\ ${ }^{2}$ School of Traffic and Transportation Engineering, Key Laboratory of Smart Transport in Hunan Province, Central South University, \\ Changsha, China \\ ${ }^{3}$ College of Transportation Engineering, Tongji University, Shanghai, China
}

Correspondence should be addressed to Jinjun Tang; jinjuntang@csu.edu.cn

Received 1 June 2017; Revised 18 September 2017; Accepted 30 October 2017; Published 12 December 2017

Academic Editor: Chunjiao Dong

Copyright (C) 2017 Ying Yan et al. This is an open access article distributed under the Creative Commons Attribution License, which permits unrestricted use, distribution, and reproduction in any medium, provided the original work is properly cited.

Operating speed is a critical indicator for road alignment consistency design and safety evaluation. Although extensive studies have been conducted on operating speed prediction, few models can finish practical continuous prediction at each point along alignment on multilane highways. This study proposes a novel method to estimate the operating speed for multilane highways in China from the aspect of the three-dimensional alignment combination. Operating speed data collected in field experiments on 304 different alignment combination sections are detected by means of Global Positioning System. First, the alignment comprehensive index (ACI) is designed and introduced to describe the function accounting for alignment continuity and driving safety. The variables used in ACI include horizontal curve radius, change rate of curvature, deflection angle of curve, grade, and lane width. Second, the influence range of front and rear alignment on speed is determined on the basis of drivers' fixation range and dynamical properties of vehicles. Furthermore, a prediction model based on exponential relationships between road alignment and speeds is designed to predict the speed of passenger cars and trucks. Finally, three common criteria are utilized to evaluate the effectiveness of the prediction models. The results indicate that the prediction models outperform the other two operating speed models for their higher prediction accuracy.

\section{Introduction}

Human-orient and safety supremacy are currently the new guidance during the period of highway construction. The traditional design speed-based alignment design approach usually only specifies the minimum value of one isolated alignment element. This designing method is prone to be inconsistent with successive elements of a road. Large amount of practical studies highlights the fact that inconsistent alignment might cause a sudden change in the characteristics of the roadway, which would lead to critical driving errors and crash risks $[1,2]$. A consistent alignment design is required to meet drivers' expectations and promotes harmonious driving behaviors. Since a number of experimental surveys state that the actual speeds adopted by drivers are considerably higher than those used to determine road design standards $[3,4]$, several countries recommend the analysis of the design consistency or safety evaluation in order to check excessive differences of operating speed on successive elements along the road [5-7]. It is noticed that the operating speed profile is the most useful tool to achieve this goal [7]. For example, Interactive Highway Safety Design Model (IHSDM) developed by the US Federal Highway Administration is wildly used for comprehensive safety assessment [8]. The current version of IHSDM checks the operating speed profile against two consistency criteria. Operating speed is an expressive parameter of driver's behavior influenced by multiple factors, such as alignment, vehicle dynamical properties, traffic flow composition, traffic management and control measures, climate, and sight distance. The 85th percentile of the free-flow speed distribution is commonly used to represent operating speed for design consistency evaluation $[1,8]$.

There are extensive literatures on operating speed prediction models in which the variables and the model constructions vary considerably. Most models focus on horizontal 
curve by assuming constant speed on curves and therefore deceleration and acceleration that occur entirely on the approach tangent and on the departure tangent [3]. Lamm et al. [9] considered the curve radius to be the most significant indicator in determining the operating speed and used it as the dominant independent variable to predict operating speed on horizontal curves. They also established a process and a classification system to evaluate horizontal design consistency. Islam and Seneviratne [10] reported the differences on feature points of alignment and established the operating speed regression model on three sites of curve. McFadden and Elefteriadou [11] combined the degree of curvature, length of curve, deflection angle, and the speed on approach tangent to make a regression analysis. Krammes et al. [12] developed an operating speed prediction model in which all the variables are related to the geometry characteristics of the curve to evaluate horizontal alignment consistency based on data collected from 138 curves. Bucchi et al. [13] conducted the estimation of operating speed on large grade sections and sharp curve with radius from $25 \mathrm{~m}$ to $170 \mathrm{~m}$ for the rural road. Some similar speed profile models mostly used curve radius (radius or degree of curvature) as the predictor [11, 14-17].

Meanwhile, previous works introduced the vertical alignment influences on operating speed [18]. Jessen et al. [19] studied the potential influences of mileage, grade of vertical curve, crash barrier, intersection, lane width, and volume on operating speed by collecting the car data on 70 vertical curves. Fambro et al. [20] presented that the sight distance was constrained by the vertical curvature which consequently determined the operating speed. Moreover, vertical grade, vertical curve type, and rate of vertical curvature were considered in the prediction models. The methodology in the IHSDM adopted these equations [8]. Gibreel et al. [21] investigated the operating data on three-dimensional alignments involving sag and crest vertical curves in Ontario and set up the reliable operating speed prediction models for two-lane highways. In addition, other models using statistical methods including simple linear regression, multiple linear regressions, and nonlinear regression were built up on the basis of analysis between alignment variables and operating speed [22-24]. By contrast, Brazil model [25] was put forward according to the mechanical properties and driving behaviors. This model also presented the clear explanation for the restriction factors to improve the accuracy of prediction. Moreover, artificial neural network and simulation technique were introduced to estimate operating speed [26, 27].

Numerous studies have been completed for passenger car operating speed prediction and design consistency on rural two-lane highways $[13,16]$. Relatively few researches, however, are conducted for trucks on multilane highways [28, 29]. J. E. Leisch and J. P. Leisch [30] found that an increase in vertical grade or length of vertical curve had much significant influence on truck speed than car speed. They also suggested that the speed profile models for trucks can be constructed by considering both horizontal and vertical alignments. In this regard, another concern has to be stressed. Most of the existing two-dimensional (2D) models which only considered horizontal and vertical curve have much lower values of coefficient of determination due to the cross section missed in the model $[6,12,17]$. Gibreel et al. [21] proposed that the maximum differences between the predicted and the observed speed using three-dimensional (3D) model and 2D model on some sites reached $35 \%$. In addition, most existing models are based on spot speed data collected by measuring the individual speeds of a sample of the vehicles passing a given spot [31]. They assumed that constant speed occurs on curves and therefore deceleration and acceleration entirely occur on the approach tangent and on the departure tangent. With these assumptions, spot speed data are collected at the center of the horizontal curve and at the midpoint of the preceding tangent. However, the maximum and minimum speeds may not occur, respectively, at the center of tangents and curves. Since the speed data are not collected at the beginning and the ending deceleration or acceleration points, these models do not accurately represent drivers' behavior. Therefore, previous works mainly calculated the speed of the feature points (i.e., the midpoint of horizontal curve or preceding tangent) of alignment using spot speed data which is usually accompanied by human error and cosine error [10]. In fact, the analysis of an individual point may blur the change pattern of operating speed and disregard the continuity of speed variation. On the basis of the overall state of the art, few of them can conduct the operating speed at each point along the road $[16,20]$.

In terms of limitations in aforementioned methods, it is challenging to design different approaches to explore a comprehensive representation of the operating speed. The report E-C151 of the Transportation Research Board [32], a thorough review of the operating speed all over the world which also underlined the requirements for novel speed models for different countries because speed behavior was influenced by multiple factors, significantly differs among regions. Recently, limited studies on continuous operating speed prediction were developed through relationships analysis between speed at all points and geometry alignment [31, 33-35]. These models provided a potential for a more accurate investigation of driver's behavior.

The main objective of the research in this paper is to propose a continuous operating speed prediction model for passenger cars and trucks on multilane highways. This new methodology, for the first time, formulates a threedimensional alignment comprehensive index (ACI) combined with driver's visual characteristics and vehicle dynamic properties to achieve higher accurate and reliable speed estimation at each point along the roadway. This could be useful for researchers to evaluate alignment design consistency and determine alignment features.

\section{Methodology}

2.1. Basic Hypotheses. Operating speed is affected by multiple factors. How to find the key information from complex influence factors is critical for accurate prediction. Based on the analysis of the relation among operating speed, alignment, and other influence factors, the basic hypotheses are summarized as follows: 
(1) Operating speed varies with the change of road condition along the driving direction.

(2) The comprehensive influence of alignment on operating speed is not only mutually independent, but also not equivalent to a simple linear overlay. As a quantitative indicator to characterize horizontal, vertical, and cross section alignment, the road alignment comprehensive index is related to the speed variation.

(3) Operating speed on a certain section is related to alignment features on this section and also affected by the range of a certain length of alignment between rear segment and front segment.

These three assumptions which focus on the influences of front and rear alignment on operating speed are in line with the general driving rules of vehicles run on highway. Meanwhile, the continuity of operating speed in space is also taken into account.

\subsection{Three-Dimensional Alignment Comprehensive Index (ACI) Description Model}

2.2.1. Alignment Comprehensive Index. An ACI is defined as a mathematical indicator $f$ which can characterize the influence of indices on alignment continuity and driving safety by considering the three-dimensional geometric features of horizontal, vertical, and cross section alignment.

It is indicated that one point corresponds to a unique value of $f$ which describes the comprehensive geometry features of various indices on each point and also reflects the amount of the information perceived by drivers. According to the influence of alignment on the driving safety, the consistent relationship between alignment and $f$ is represented as a smaller value of $f$ contributes to better alignment. In other words, the alignment corresponding to a smaller $f$ will be more benefit for driving.

The key idea of method lies in setting up the horizontal, vertical, and cross section alignment model, respectively, and then integrating them into the ACI description model. According to the definition of ACI and the works in [31], the most significant independent variables influencing the operating speed and corresponding to each point have been taken into account.

2.2.2. Horizontal Alignment Description Model. Three variables including radius, change rate of curvature, and deflection angle of curve are considered in the horizontal alignment description model. Generally, these three variables can represent lateral force, rotation rate of the steering wheel, and deflection angle of driver's vision. When vehicles travel on a horizontal curve with greater curvature, the worse lateral stability may be generated due to the larger centrifugal [36]. The mutations of curvature are prone to driving risk even crashes. Thus, the consistent relationship between curvature and $f$ can be determined as the larger the curvature, the smaller $f$. Similarly, the more rapidly the curvature changes on a spiral curve, the greater the impact on the driver is because of the workload on adjusting the steering wheels and ultimately the greater likelihood of danger. Generally, drivers need to shift their eyes or turn their heads to focus on a front point as the trajectory changes. A sharp change of deflection angel of curve would aggravate range of driver's vision. This is also harmful for safe driving. Therefore, $f$ increases as these two variables become larger.

The relationship between each individual indices and the intermediary variable is applied to transform and unify the change laws of each index and the comprehensive index. The vertical and cross section correction model also use the same research ideas, in which speed is often taken as the intermediary variable.

In some traditional regression models, the speed at a given radius is formulated as an ordinary linear model $(V=$ $a-b / R)$ or power model $\left(V=a R^{b}\right)$. Combining with the test data, the relation between operating speed and radius are analyzed by using these two forms function firstly. It can be concluded that power model has limitation with radius less than $250 \mathrm{~m}$. The variation is too slight to reflect the influence of radius on operating speed. However, it is apparently rare for highways with radius less than $250 \mathrm{~m}$. On the contrary, the speed variation in linear model is too strong and even negative value occurs with the radius less than $700 \mathrm{~m}$. However, this is a frequent occurrence that the radius of horizontal curve is less than $700 \mathrm{~m}$. Thus, power function is adopted to demonstrate the relation between $f$ and radius. Moreover, exponential model $[9,11,12]$ is widely used to predict the variation of operating speed with change rate of curvature and deflection angle of curve. Based on above analyzes of each indicator, these models can be generalized as (1) by using a multiple exponential with linearized function to form the horizontal ACI $\left(f_{H}\right)$ model:

$$
f_{H}=m R^{n} \exp \left(a_{1} \mathrm{CCR}+b_{1} \mathrm{DF}\right),
$$

where $R$ is curvature; CCR represents change rate of curvature; DF denotes deflection angle of curve; $m, n, a_{1}$, and $b_{1}$ are parameters.

2.2.3. Vertical Alignment Description Model. In the vertical alignment description model, grade is considered as the main variable. It can be concluded that the driving safety would become worse as the grade increases no matter on downhill or uphill due to the insufficient sighting distance or speeding. From the point of the definition of the consistent relationship between $f$ and alignment index, $f$ increases with the increase of grade. Although the variation of $f$ with grade is easy to know, the quantitative relation still remains unclear. That is, the intermediary variable, speed with the absolute value of grade, has a distinct trend. According to the initial data analysis, speed decreases as grade varies from downhill to uphill. So the correlation between grade and the vertical ACI $\left(f_{V}\right)$ is firstly expressed as linear regression is analyzed [20]. However, in fact, speed varies slightly when the grade ranges between $-2 \%$ and $2 \%$, whereas the grade is greater than $3 \%$ or less than $-3 \%$, and the variation of speed increases with nonlinear function. Moreover, for the positive and negative grade, the corresponding $f_{V}$ has a different value range. 
Consequently, the vertical ACI model (see (2)) is developed based on the improvements of the linear regression equation:

$$
f_{V}=a_{2} i|i|+b_{2} i+c_{2}
$$

where $i$ is grade; $a_{2}, b_{2}$, and $c_{2}$ are parameters.

2.2.4. Cross Section Alignment Correction Model. In the cross section alignment model, the five independent variables are utilized in model, including lane width, lane number, widths of right and left shoulder, and the adjustment coefficient which represents the variation of pavement width because of the transition from common road to bridge or tunnel. Generally, the interaction between adjacent vehicles along the driving direction is smaller on the wider roadway. Such driving environment also offers greater driving convenience and freedom due to a wider vision field. It indicates that wider roadway is more favorable to the traffic. In other words, $f$ decreases with the increase of lane width, lane number, and the left and right shoulder width. However, operating speed increases as the width of pavement becomes large. In the findings of Harwood et al. [37], the regression relationship between speed reduction and cross section is presented. It also suggests cumulative effects on the speed due to variations in lane and shoulder width [17]. For example, for a given cross section composed by a lane width smaller than $3.6 \mathrm{~m}$ and a shoulder width smaller than $1.8 \mathrm{~m}$, the reduction in speed is the sum of the individual effects caused by each variable. On the basis of field investigation, the cross section ACI $\left(f_{C}\right)$ model is set up in terms of the width standard of eight-lane highway and the reduction percentage of speed related to cross section width as

$$
\begin{aligned}
f_{C} & =\beta \cdot \ln \left(a_{3} B^{2}+b_{3} B+c_{3}\right)+\xi, \\
B & =n_{3} \cdot L+w_{1}+w_{2},
\end{aligned}
$$

where $\beta, a_{3}, b_{3}$, and $c_{3}$ are the parameters; $\xi$ is the adjustment coefficient of the bridge and tunnel; $B$ is the total width of single carriageway section; $L$ is the width of a single lane; $n_{3}$ is the number of lanes; $w_{1}$ and $w_{2}$ are the widths of the left and right road shoulders.

2.2.5. Model Integration. A horizontal alignment in a roadway refers to the alignment or how "straight" the roadway section is. A vertical alignment refers to a roadway's change in elevation or the "flatness" of the roadway. With respect to the road information perceived by drivers, it is not only related to alignment itself but also involved operating speed. In this paper, the challenge is how to quantify the road alignment information and integrate the horizontal, vertical, and cross section alignment ACI into a 3D ACI description model serving for the operating speed prediction. Because people's perception to the distance, shape, and speed of the objects in real space depends on continuous learning and experience [20], it is really difficult to achieve effective identification performance. Currently, the perspective images are generally used to depict the road section from high view (bird's eye view). However, the analysis of these images is qualitative and subjective [38].
It is worth mentioning that tangent is a radial ray expanded from a vanishing point in the fields of vision of drivers [39]. Tangent is the most recognizable shape for drivers, and the understanding of other alignment is usually acquired based on the comparison with tangent. Drivers could firstly predict the consistency between the front and the current horizontal alignment, focusing primarily on the operating speed rather than on the direction. Through a change of sight distance, drivers can attain information about vertical alignment. Given the fact that the cross section alignment rarely changes, the perceptions of drivers in different cross sections are nearly the same and are less dependent on the change of horizontal and vertical alignments.

During construct ACI model, we consider the following several reasons: first, in some traditional regression models, the speed at a given radius, change rate of curvature, and deflection angle of curve are formulated as an ordinary linear model, power model, or exponential model $[9,11,12]$. We referenced these model forms and generalized these models by using a multiple exponential with linearized function to form the horizontal ACI $\left(f_{H}\right)$ model.

Second, we found speed decreased as grade varied from downhill to uphill. So we analyze the correlation between grade and the vertical ACI using the linear regression firstly [20]. However, in fact, speed varies slightly when the grade is between $-2 \%$ and $2 \%$, whereas the grade is greater than $3 \%$ or less than $-3 \%$, and the variation of speed increases with nonlinear function. Moreover, for the positive and negative grade, the corresponding $f_{V}$ has a different value range. Consequently, the vertical ACI model (see (2)) is developed based on the improvements of the linear regression equation.

Third, in the findings of Harwood et al. [37], the regression relationship between speed reduction and cross section is presented. It also suggests cumulative effects on the speed due to variations in lane and shoulder width [17]. On the basis of field investigation, the cross section ACI $\left(f_{c}\right)$ model is set up in terms of the width standard of eight-lane highway and the reduction percentage of speed related to cross section width.

Moreover, the challenge in this study is how to integrate the horizontal, vertical, and cross section alignment ACI into a 3D ACI description model. By considering alignment design features, several research findings and the cross section alignment adjustment form mentioned in Highway Capacity Manual 2010 [40], and the ACI description model is put forward based on the sensitivity to each alignment index.

After repeated trial calculation and parameters calibration, the three-dimensional alignment comprehensive index description function is set up finally. The ACI description model is put forward based on the sensitivity to each alignment index as shown in

$$
f=f_{H} f_{V}+f_{C}
$$

The reasons we choose these indicators are shown as follows: First, on the basis of data analysis, we studied the correlation among the single index, operating speed, and traffic safety, including length of tangent, radius of horizontal curve (curvature), curvature rate, curve length deflection 
angle of horizontal curve, grade, length of vertical grade, and lane width. Then, we selected the indexes which were often used to establish operating speed model in the related achievements at home and aboard. In summary, the indexes which have great influence on operating speed and safety were selected preliminarily.

Secondly, according to the characteristics of road alignment, these indexes can be divided into two categories. One category is the section design index corresponding to the milepost, mainly including radius, curvature rate, curve length deflection angle of horizontal curve, grade, lane number, lane width, and shoulder width. Another category is the indexes along the roadway, such as tangent length, curve length, length of vertical curve length, and spiral length.

The alignment comprehensive index is based on the road section, so the model of ACI mainly considers the first category indexes, and the second category indexes will be selected in the operating speed prediction model.

2.3. Determination of Influence Range. This study emphasizes a continuous speed prediction which is more accurate than other researches on operating speed with a single alignment index. The section speed is selected as objects through discretizing the continuously variable operating speed. Although the alignment comprehensive index and operating speed are divided into points, the operating speed on a certain section is always related to the front and rear alignments within a certain length. The speed of one point is the cumulative result of speed variation on rear alignment that has already traveled. On the other hand, a certain range of alignment ahead decides the driver's expectation of acceleration and deceleration based on the perception of the visual information obtained at the present moment. So the influence range of front and rear alignment on current section speed should be determined.

The visual characteristics of drivers are the most important factor affecting the change in operating speed. The key step to determine the influence range of front alignment is to quantify environmental factors of visual information to a digital index, then using this digital index to analyze the influence of front alignment on operating speed.

Road alignment forms a visual sensitive area in the drivers' view plane, generally known as fixation range [41], including the invisible region, rear view region, and front view region. Using as the prejudgment of alignment conditions ahead, the front view region is the main influence range of the operating speed. Easa and $\mathrm{He}$ [42] showed that driver's visual demand interval was generally approximately $3 \mathrm{~s}$. Therefore, $3 \mathrm{~s}$ trip is used as the starting point of the most sensitive position in driving process, which is the nearest point of the front alignment influence. Depending on the speed, driver vision is usually focused further as the speed increase. However, because of the influences of elevation fluctuation and sight distance on curves, the maximum fixation distance on curves may be closer than that on tangents. According to the current China Technical Standard of Highway Engineering (JTG B01-2014) [43], a certain stopping sight distance on curve segments is specified. When the design speed is $120 \mathrm{~km} / \mathrm{h}$, the recommended stopping sight distance is $210 \mathrm{~m}$. Thus, 1.2 times stopping sight distance is adopted as the farthest fixation point of front alignment influence on the basis of general consideration. To take the maximum design speed $120 \mathrm{~km} / \mathrm{h}$ into account, the influence range of front alignment is determined from $100 \mathrm{~m}$ to $250 \mathrm{~m}$.

Operating speed on a current section is the result of cumulative speed change of the rear-traveled sections. The speed differences existing between the front and rear sections are induced by the acceleration and deceleration of a vehicle. Thus, the influence range of rear alignment can be approximately characterized by the acceleration and deceleration distance. According to several previous studies [44, 45], the deceleration or acceleration rates mainly depend on the radius of the curve and its locations. However, the acceleration and deceleration models using the spot speed data do not reflect driver's actual behavior because the starting and ending points of the speed transition can not be determined a priori. Therefore, the actual acceleration and deceleration rates cannot be accurately obtained. Moreover, the speed transition length depends more on driver characteristic (such as age, gender, purpose of the trip, and distance traveled) than on the alignment transition design [44].

Thanks to the continuous speed profiles observed for each individual trajectory, 15th and 85th percentile speeds are, respectively, $102 \mathrm{~km} / \mathrm{h}$ and $123 \mathrm{~km} / \mathrm{h}$ for car compared to $69 \mathrm{~km} / \mathrm{h}$ and $81 \mathrm{~km} / \mathrm{h}$ for truck. Because the probability of occurrence of speed decelerating from 85th percentile to 15 th percentile is generally low, it is relatively conservative and safe to consider these speed intervals as the speed differences in deceleration process. Consequently, according to the recommended deceleration of $0.9 \mathrm{~m} / \mathrm{s}^{2}$ for cars and $0.35 \mathrm{~m} / \mathrm{s}^{2}$ for trucks in our project report [46], the influence range of the rear alignment can be determined as $200 \mathrm{~m}$.

2.4. Structure of Prediction Model. From the given analysis, the operating speed $V$ of current section contains the following two parts: $V_{1}$ and $\Delta V$. The initial speed $V_{1}$ represents the accumulation of operating speed within the $200 \mathrm{~m}$ influence range of rear alignment. $\Delta V$ means acceleration or deceleration according to the alignment features within the effective fixation range from $100 \mathrm{~m}$ to $250 \mathrm{~m}$ ahead. These two variables are jointed to determine the operating speed $V$ of current section, and the relationship can be expressed as

$$
V=V_{1}+\Delta V
$$

In (5), $V_{1}$ and $\Delta V$ are also determined by the accumulated values of ACI of the front and rear influence ranges. However, the influences of front and rear alignment on operating speed are different. Therefore, considering speed superposition principle, this study puts forward the form of speed prediction model as (6). The criteria used for identifying the prediction performance are based on the highest coefficient 
TABLE 1: Site geometric design characteristics.

\begin{tabular}{|c|c|c|c|c|}
\hline Variable & Minimum & Maximum & Mean & Standard deviation \\
\hline Design speed $(\mathrm{km} / \mathrm{h})$ & 60.00 & 120.00 & 108.32 & 15.62 \\
\hline Horizontal curve radius (m) & 400.00 & 3500.00 & 868.05 & 218.65 \\
\hline Curve length (m) & 284.22 & 1155.48 & 902.65 & 89.37 \\
\hline Deflection angle of horizontal curve & 6.51 & 71.12 & 37.22 & 12.36 \\
\hline Length of spiral curve & 135.00 & 1800.00 & 728.93 & 106.32 \\
\hline Tangent length (m) & 121.00 & 2245.00 & 1253.28 & 185.21 \\
\hline Grade (\%) & -5.40 & 5.00 & 0.63 & 2.57 \\
\hline Length of vertical grade (m) & 160.00 & 1300.00 & 776.89 & 165.79 \\
\hline Lane number & 4.00 & 8.00 & 6.75 & 0.93 \\
\hline Lane width (m) & 3.50 & 3.75 & 3.70 & 0.12 \\
\hline Left shoulder width [hard/soft] (m) & {$[1.00 / 0.75]$} & {$[1.25 / 0.75]$} & {$[1.17 / 0.75]$} & {$[1.02 / 0]$} \\
\hline Right shoulder width [hard/soft] (m) & {$[3.00 / 0.75]$} & {$[3.50 / 0.75]$} & {$[3.35 / 0.75]$} & {$[0.56 / 0]$} \\
\hline
\end{tabular}

of determination $R^{2}$, the significance of each predictor, and the logical explanation of the model

$$
\begin{aligned}
& V=a \exp \left[b F_{(r 200 \mathrm{~m})}+c\left(F_{(f 250 \mathrm{~m})}-F_{(f 100 \mathrm{~m})}\right)\right] \\
& F_{(f 250 \mathrm{~m})}=\left|\int_{0}^{250} f(l) \cdot d l\right| \\
& F_{(f 100 \mathrm{~m})}=\left|\int_{0}^{100} f(l) \cdot d l\right| \\
& F_{(r 200 \mathrm{~m})}=\left|\int_{-200}^{0} f(l) \cdot d l\right|
\end{aligned}
$$

where $V$ is the operating speed on the current point; $f(l)$ represents the ACI function; $F_{(f 250 \mathrm{~m})}-F_{(f 100 \mathrm{~m})}$ is the ACI accumulated value in the influence range of front alignment; $F_{(r 200 \mathrm{~m})}$ denotes the ACI accumulated value in the influence range of rear alignment; $F_{(f 250 \mathrm{~m})}, F_{(f 100 \mathrm{~m})}$, and $F_{(r 200 \mathrm{~m})}$ can be calculated using (7), (8), and (9); $a, b$, and $c$ are the coefficient; other parameters are introduced before.

\section{Data Collection}

Speed data were collected on Shenda Highway (eight-lane in two directions, design speed of $120 \mathrm{~km} / \mathrm{h}$ ), Shenshan Highway (six-lane in two directions, design speed of $120 \mathrm{~km} / \mathrm{h}$ ), and Shendan Highway (four-lane in two directions, design speed of $100 \mathrm{~km} / \mathrm{h}, 80 \mathrm{~km} / \mathrm{h}$, and $60 \mathrm{~km} / \mathrm{h}$ on different sites) for both directions in two time periods: from June to October 2013 and from March to May 2014, to establish prediction model. The testing data set used to validate the proposed model was collected on Taijiu Highway from April to May 2014.

The test sites consists of two types alignment combinations including 158 sections of a sag curve combined with a horizontal curve and 146 sections of a crest curve combined with a horizontal curve. In all cases, there exists a spiral transition between tangent and circular curve. The geometric design data were acquired from road alignment design documents. The data include radius of horizontal curve, deflection angle of horizontal curve, length of horizontal, vertical and spiral curve, grade, length of tangent, lane width, number of lane, shoulder width, and the milepost of each feature points. Table 1 summarizes the main geometric features of the test alignment.

There are several instruments for speed data collection, including Global Positioning System (GPS), radar gun, loop detector, video detection system, and infrared detector. By contrast with the features of each instruments, this study applied GPS devices placed on passenger cars and trucks to obtain the individual continuous operating speed profiles. Drivers were proved to be not biased by the presence of GPS device [32], and therefore the operating speed data collected in the test were reasonable to reflect the normal driving behavior. GPS also can provide high accuracy of the spatial coordinates with a frequency of $1 \mathrm{~Hz}$. Therefore, it is possible to know the position and calculate the speed of each point.

The passenger cars or trucks which would travel through the observed sections were recruited in toll stations to participant this project. All the participants were informed that speed data would be used only for research purpose; thus they were free to select their speed according to their driving habits.

The experiments were carried out during daytime, offpeak periods, in sunny day, under free-flow conditions which are typically defined as having time headways of at least 5 or $6 \mathrm{~s}[18,34]$, and on the condition of dry pavements. In the experiment, one test personnel sat in the rear of the car so as to record the nonfree flow conditions (i.e., carfollowing or lane-changing). In the further analysis, all the data influenced by the external factors were discarded in the data processing. More than 340 passenger cars and 287 trucks were investigated at each selected site, ensuring a minimum of 100 speed data of each type vehicle per direction at each point for operating speed estimation.

In order to explore the operating speed prediction models, the following speed data were processed subsequently based on the initial analysis of continuous speed profile of each vehicle and the reference of data collection position proposed by Gibreel et al. [21]: 


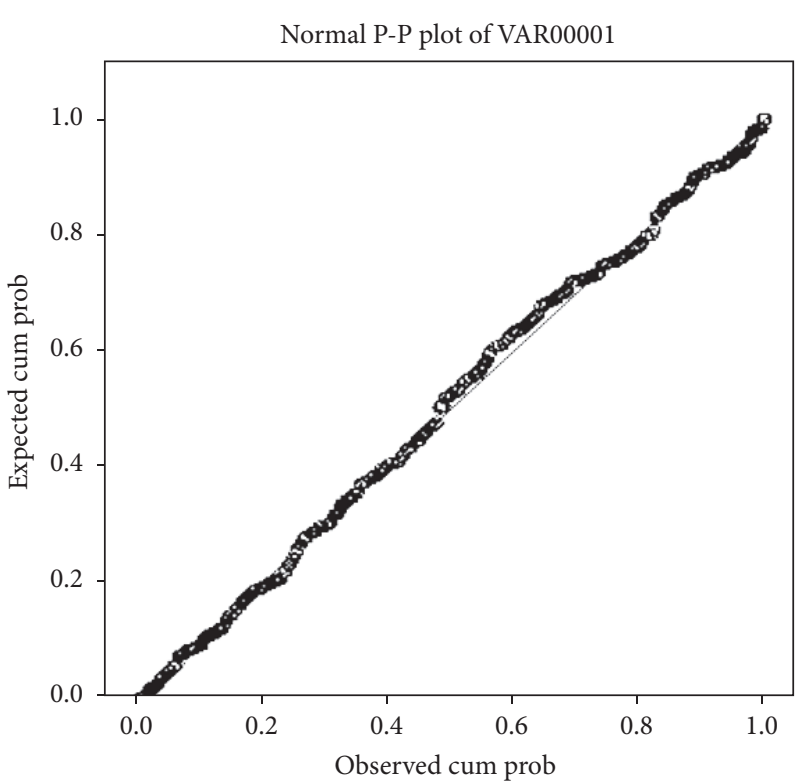

(a)

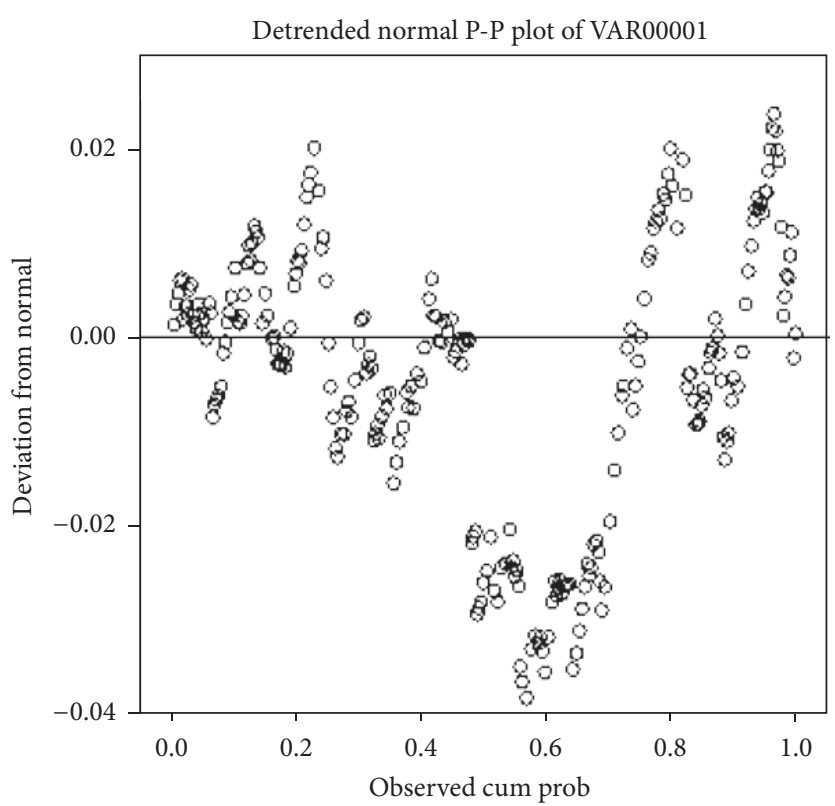

(b)

FIGURE 1: Normal probability plot of cars. (a) Cumulative probability distribution. (b) Deviation from Normal.

(1) Points were $0 \mathrm{~m}, 50 \mathrm{~m}$, and $100 \mathrm{~m}$ on the approach tangent before the beginning of the spiral curve where drivers may change speed but not completely because of the effect of the 3D combination ahead.

(2) Point was the start point of a horizontal curve where drivers could finish the speed selection from a tangent to transition of a curve.

(3) Points were the middle point of tangent, spiral curve, and horizontal curve.

(4) Point was the end point of a horizontal curve and the beginning of spiral curve.

(5) Points were $0 \mathrm{~m}, 50 \mathrm{~m}$, and $100 \mathrm{~m}$ on the departure tangent after the end of spiral curve where drivers may select speed according to the transition from curve to tangent.

If the length of tangent is short, the processed points were reduced correspondingly. Furthermore, the $3 \sigma$ statistical criterion [2] was used to check the homogeneity distribution around the mean and the maximum deviation of speed distribution equal to $3 \sigma$. Consequently, speed data from more than 2400 points were measured. Moreover, an important issue is to verify the speed distribution for each type site (i.e., tangent and curve) because it is found that speed distribution differed from the curve to the tangent [11].

The distribution characteristics of speed data are analyzed based on histogram features of overall frequency of speed sample. Normal, Weibull, Gamma, and Logistic distribution are applied to finish distribution fitting and frequency testing. Normal probability plot is applied to accomplish qualitative test and determine the preliminary distribution form. In Figure 1(a), the horizontal and vertical coordinates represent the theoretical and the actual cumulative probability, respectively. It can be seen that the data points in the graph coincide with the theoretical diagonal line. Figure $1(\mathrm{~b})$ is the residual plot calculated based on normal distribution. The data are basically distributed over the horizontal line without regular fluctuations. This could be a hint that the data obey normal distribution. After using the Pearson's goodness fit test and Kolmogorov-Smirnov test, the tangents and curves are identified with Normal and Logistic distribution, respectively. Therefore, the operating speed that is 85 th percentile speeds measured on 2400 points is available for further calculation.

\section{Results Analysis and Discussion}

4.1. Parameters Calibration and Sensitivity Analysis. First, according to the regulations of minimum and maximum radius of curve on highway, the influence weight in (1) is obtained. Second, the parameters in (2) are determined by using the limitations of grade in specification and influence ratio of grade on speed. Third, the coefficients in (3) are also fixed taking the reduction relation between pavement width and speed into consideration.

After repeated trial calculation and parameters calibration, the three-dimensional alignment comprehensive index description function is set up as follows:

$$
\begin{aligned}
f(l)= & \left\{430 \cdot R^{-0.757} \exp [3000 \mathrm{CCR}+0.0005 \mathrm{DF}]\right\} \\
& \cdot f_{V}+f_{C}, \\
f_{V}= & 0.012 \cdot i \cdot|i|+0.04 \cdot i+1.0, \\
f_{\mathrm{CA}}= & -28.57
\end{aligned}
$$




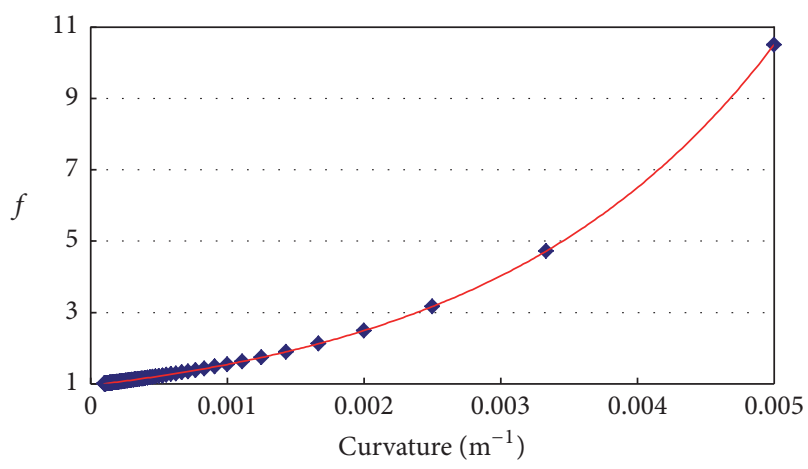

(a)

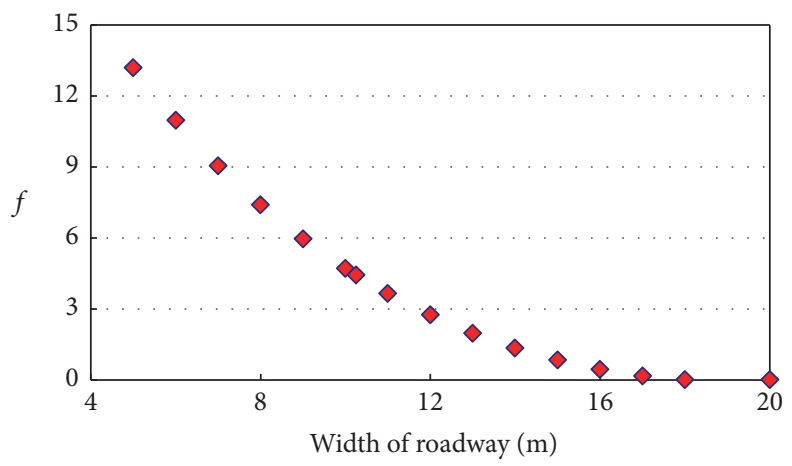

(c)

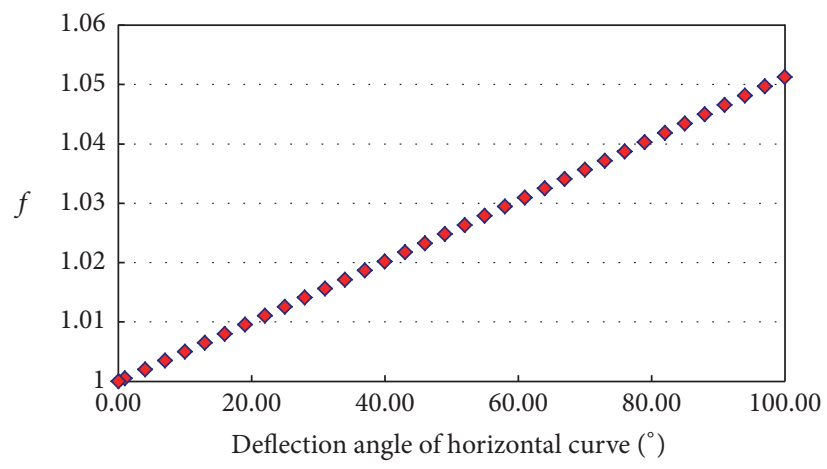

(b)

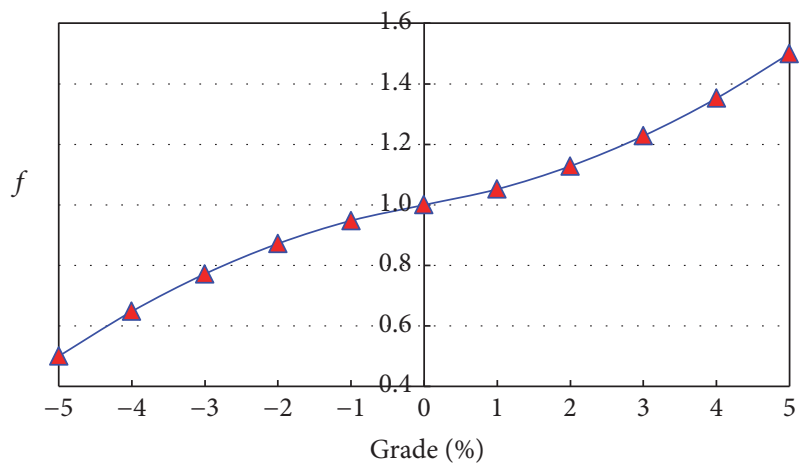

(d)

Figure 2: Relation between single index and $f$. (a) Curvature. (b) Deflection angle of horizontal curve. (c) Width of roadway. (d) Grade.

$$
\begin{gathered}
\cdot \ln \left(-0.00189 \cdot B^{2}+0.0719 \cdot B+0.318\right) \\
+\xi \\
f_{\mathrm{CD}}=-20.57 \cdot \ln (0.0078 \cdot B+0.847)+\xi
\end{gathered}
$$

where $f_{\mathrm{CA}}$ and $f_{\mathrm{CD}}$ are the cross section alignment function for cars and trucks; the definitions of other parameters are the same as aforementioned.

In order to analyze the sensitivity of each index to $f$ in the description model, a single key indicator is chosen as a variable. And then the other factors in the 3D ACI model are fixed. Thus, the variation of $f$ with the single index can be seen in Figure 2.

It can be seen from Figure 2 that $f$ on curves considerably increases with the increase in curvature. $f$ is more sensitive to the curvature between 0.001 and 0.005 (i.e., radius is less than $1000 \mathrm{~m}$ ). By contrast, $f$ has little changes on curves with a curvature less than 0.001 (i.e., the radius is larger than $1000 \mathrm{~m}$ ). It indicates that horizontal curve with radius of $4000 \mathrm{~m}$ or $5000 \mathrm{~m}$ already have very slight impact on driving which is close to the effect of tangent. Notably, deflection angle of horizontal curve and width of roadway markedly affects $f$.

Figure 2(d) shows $f$ increases as a unilateral parabolic curve with the increase of grade. $f$ has very obvious sensitivity to bigger grade because of the higher requirements of vehicle dynamic performance on uphill and acceleration behavior. However, the sensitivity of $f$ is relatively weak with the grade ranging from $-1 \%$ to $1 \%$. In real driving, drivers' perceptions on such slope are usually not obvious.

Meanwhile, in order to further validate the sensitivity of ACI to alignment condition, K63 + 000-K83 + 000 and $\mathrm{K} 63+300-\mathrm{K} 65+100$ of Shendan Highway are selected to conduct relation analysis (Figures 3(a) and 3(b)). With (11), (12), and (13) substituted into (10), the ACI of this section can be obtained by using the actual alignment data.

From Figure 3(a), it can be seen that each point has different comprehensive index value as the alignment varies. In Figure 3(b), the number means the alignment combination type (i.e., 1: spiral curve, small grade; 2: spiral curve, small grade; 3: spiral curve, sag curve; 4: circular curve, sag curve; 5: circular curve, tangent grade; 6: circular curve, crest curve; 7: tangent, sag curve; 8: tangent, grade; 9: circular curve, large grade). For example, the road segment $\mathrm{K} 63+314-\mathrm{K} 63+$ 474 is located on the spiral curve and grade of $1.467 \%$. The alignment comprehensive index gradually decreases while the curvature tends to be smaller. The segment K64 + $630-\mathrm{K} 64+854$ is located on the tangent and crest curve. When grade becomes larger, the alignment comprehensive index increases slowly. Similarly, the segment after K64 + 854 is located on the tangent grade of $2 \%$ and the comprehensive index becomes stable and much smaller. It can be concluded that the results comply with consistence of the sensitivity analysis. In addition, we can see that, on the section with larger synthetic index, the variation of cumulative curve is also more obvious. This indicates that the alignment index 


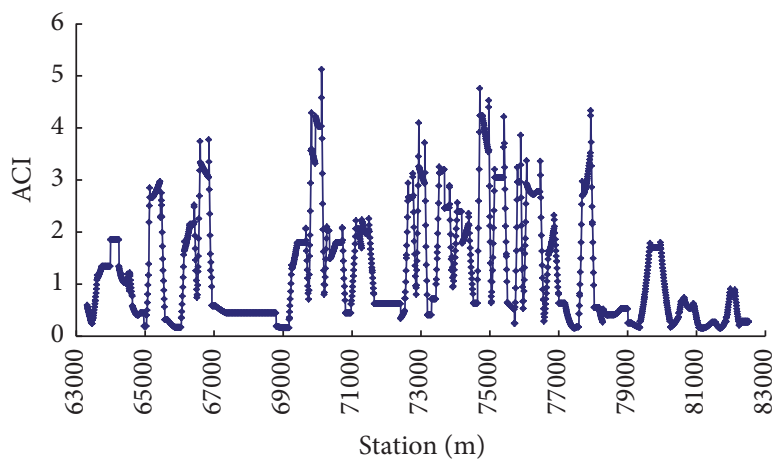

(a)

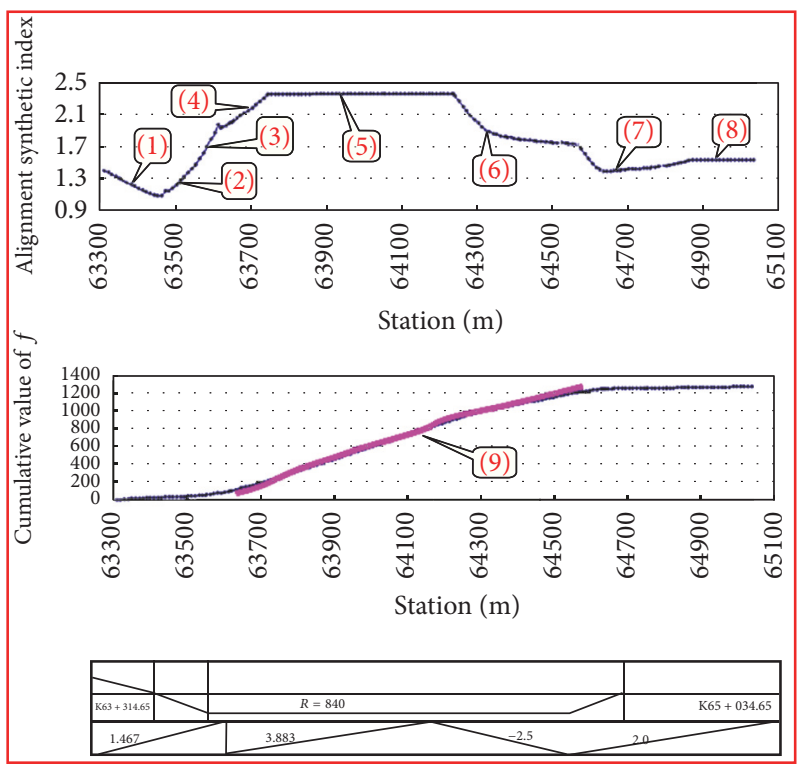

(b)

FIGURE 3: Alignment comprehensive index variations. (a) ACI at each point. (b) Distribution of cumulated alignment comprehensive index.

condition is good. On the contrary, the condition is poor. So the good corresponding relation among the alignment features, ACI, and ACI cumulative value can reflect the difference of alignment condition to a certain extent.

4.2. Establishment of Operating Speed Prediction Model. The alignment comprehensive indices are divided into two categories (i.e., I uphill and other indices and II downhill and other indices) due to the different influence degree of grade in vertical description model on operating speed.

Considering the point in integration theory, the cumulative value of the ACI in a certain length range using small spacing as a unit is equal to the integral of $\mathrm{ACI}$ in this length range. So during the calculation of the cumulative value of $\mathrm{ACI}$, it can approximately take $1 \mathrm{~m}$ as a unit to calculate one $\mathrm{ACI}$ value and then to solve the accumulation value in a certain length range. It is worthy noting that the radius value is taken as 3000 on the tangent or on the curve with more than $3000 \mathrm{~m}$ radius since it may has little influence on driving behavior. Some operating speed data and the cumulative value of I alignment comprehensive index are shown in Table 2.

Through the analysis of operating speed variation with alignment index and coefficient calibration, the following operating speed prediction models which best fit the criteria of the regression analysis are established. The predicting speed for cars can be calculated by using (14) and (15). Accordingly, (16) are suitable for the speed estimation of trucks:

$$
\begin{aligned}
& \text { (1) Cars } \\
& \begin{aligned}
& V_{\mathrm{I}, \mathrm{A}}=141.03 \cdot \exp \left[-1.35 \times 10^{-4} \cdot\left(F_{(r 200 \mathrm{~m})}\right)-6.78\right. \\
&\left.\quad \times 10^{-5} \cdot\left(F_{(f 250 \mathrm{~m})}-F_{(f 100 \mathrm{~m})}\right)\right] \\
& V_{\mathrm{II}, \mathrm{A}}=140.79 \cdot \exp \left[-9.44 \times 10^{-5} \cdot\left(F_{(r 200 \mathrm{~m})}\right)-1.07\right.
\end{aligned}
\end{aligned}
$$

$$
\left.\times 10^{-4} \cdot\left(F_{(f 250 \mathrm{~m})}-F_{(f 100 \mathrm{~m})}\right)\right] .
$$

(2) Trucks

$$
\begin{aligned}
V_{\mathrm{I}, \mathrm{D}} & =89.73 \cdot \exp \left[-1.42 \times 10^{-4} \cdot\left(F_{(r 200 \mathrm{~m})}\right)-1.24\right. \\
\quad & \left.\times 10^{-4} \cdot\left(F_{(f 250 \mathrm{~m})}-F_{(f 100 \mathrm{~m})}\right)\right], \\
V_{\mathrm{II}, \mathrm{D}} & =89.26 \cdot \exp \left[-1.20 \times 10^{-4} \cdot\left(F_{(r 200 \mathrm{~m})}\right)-1.41\right. \\
\quad & \left.\times 10^{-4} \cdot\left(F_{(f 250 \mathrm{~m})}-F_{(f 100 \mathrm{~m})}\right)\right] .
\end{aligned}
$$

4.3. Validation of Effectiveness. Four statistical validation indicators are applied to evaluate the effectiveness of prediction model including Goodness of Fit test, F-test, Residual analysis, and $t$-test. The test results of I operating speed prediction model (see (14)) for cars as an example are listed at Table 3 and Figure 4.

In [34], the correlation coefficient $R^{2}$ between predicted average speed and variables including length of the horizontal curve, radius of the horizontal curve, and local longitudinal grade is 0.63 . In [35], the correlation coefficient $R^{2}$ between predicted average speed and variables including averaged curvature, average of grade for upgrades, and average of grade for downgrades is $0.625 . R^{2}$ in this study is about 0.6523 , which shows the relationship between ACI and speed is related when the great amount of data processed is taken into account. It is also indicated that the significance of model is good due to significance $F$ much smaller than significant level of 0.05 . The regression coefficients of the variables in the model are, respectively, $4.949,-0.00013$, and -0.000068 . This finding illustrates that variables pass the significance test. In addition, the facts that the points on the residual analysis 
TABLE 2: Test data for cars.

\begin{tabular}{|c|c|c|c|c|}
\hline Milepost & Grade (\%) & $F_{(r 200 \mathrm{~m})}$ & $F_{(f 250 \mathrm{~m})}-F_{(f 100 \mathrm{~m})}$ & Operating speed $(\mathrm{km} / \mathrm{h})$ \\
\hline $\mathrm{K} 65+985$ & 1.47 & 1106.47 & 1252.86 & 111.82 \\
\hline $\mathrm{K} 66+049$ & 1.47 & 1103.77 & 1354.53 & 108.15 \\
\hline $\mathrm{K} 66+095$ & 1.97 & 1125.53 & 1393.17 & 114.22 \\
\hline K66 + 139 & 2.61 & 1228.09 & 1419.28 & 109.14 \\
\hline $\mathrm{K} 66+281$ & 4.64 & 1705.29 & 1203.53 & 110.35 \\
\hline $\mathrm{K} 66+423$ & 4.90 & 1890.35 & 1488.18 & 98.94 \\
\hline $\mathrm{K} 66+465$ & 4.90 & 1878.74 & 1617.33 & 98.76 \\
\hline $\mathrm{K} 66+513$ & 4.90 & 1740.86 & 1624.97 & 92.63 \\
\hline $\mathrm{K} 69+105$ & 1.09 & 1099.20 & 1162.30 & 113.32 \\
\hline $\mathrm{K} 69+263$ & 2.42 & 1191.36 & 1330.58 & 113.03 \\
\hline $\mathrm{K} 69+565$ & 5.00 & 1778.82 & 1160.20 & 106.55 \\
\hline $\mathrm{K} 69+664$ & 5.00 & 1790.49 & 1554.80 & 101.46 \\
\hline $\mathrm{K} 69+752$ & 5.00 & 1646.05 & 1626.90 & 97.16 \\
\hline $\mathrm{K} 69+829$ & 4.68 & 1642.82 & 1585.98 & 99.02 \\
\hline $\mathrm{K} 69+900$ & 4.20 & 1817.33 & 1556.34 & 96.14 \\
\hline $\mathrm{K} 69+974$ & 3.71 & 2129.76 & 1276.69 & 92.91 \\
\hline $\mathrm{K} 70+119$ & 3.40 & 2114.19 & 1183.25 & 94.90 \\
\hline $\mathrm{K} 76+370$ & 1.50 & 1866.46 & 1056.80 & 103.44 \\
\hline $\mathrm{K} 76+469$ & 1.50 & 1908.52 & 981.25 & 105.93 \\
\hline $\mathrm{K} 76+575$ & 1.17 & 1718.65 & 1112.75 & 108.10 \\
\hline $\mathrm{K} 76+645$ & 0.01 & 1456.53 & 1062.38 & 104.18 \\
\hline $\mathrm{K} 77+555$ & 1.62 & 1090.20 & 1346.95 & 110.63 \\
\hline $\mathrm{K} 77+592$ & 1.62 & 1096.66 & 1336.88 & 112.39 \\
\hline $\mathrm{K} 79+366$ & 1.39 & 1112.55 & 1061.81 & 114.87 \\
\hline $\mathrm{K} 79+657$ & 0.60 & 1450.03 & 1240.57 & 110.63 \\
\hline $\mathrm{K} 79+725$ & 0.60 & 1570.39 & 1240.58 & 105.58 \\
\hline $\mathrm{K} 79+808$ & 0.60 & 1644.95 & 1196.11 & 106.98 \\
\hline $\mathrm{K} 79+885$ & 0.60 & 1654.10 & 1087.42 & 109.76 \\
\hline $\mathrm{K} 79+959$ & 0.60 & 1654.24 & 952.85 & 107.44 \\
\hline
\end{tabular}

TABLE 3: Statistical test of speed prediction model.

\begin{tabular}{|c|c|c|c|c|c|c|}
\hline \multicolumn{7}{|c|}{ Goodness of fit test } \\
\hline & Multiple $R$ & & \multicolumn{4}{|c|}{0.8077} \\
\hline & $R$ square & & \multicolumn{4}{|c|}{0.6523} \\
\hline & Adjusted $R$ square & & \multicolumn{4}{|c|}{0.6330} \\
\hline & Standard error & & \multicolumn{4}{|c|}{0.0362} \\
\hline & Observed value & & \multicolumn{4}{|c|}{39} \\
\hline \multicolumn{7}{|c|}{$F$-test } \\
\hline & $\mathrm{df}$ & SS & MS & \multicolumn{2}{|c|}{$F$} & Significance $F$ \\
\hline Regression analysis & 2 & 0.0887 & 0.0444 & \multicolumn{2}{|c|}{33.7746} & $5.51 E-09$ \\
\hline Residual & 36 & 0.0473 & \multirow[t]{2}{*}{0.0013} & & & \\
\hline Total & 38 & 0.1360 & & & & \\
\hline \multicolumn{7}{|c|}{$t$-test } \\
\hline & Coefficients & Standard error & $t$ stat & $P$ value & Low limit & Upper limit \\
\hline Intercept & 4.9490 & 0.0381 & 129.9758 & $1.04 E-49$ & 4.8718 & 5.0262 \\
\hline$X$ variable 1 & -0.0001 & $1.86 E-05$ & -7.2385 & $1.6 E-08$ & -0.0002 & $-9.7 E-05$ \\
\hline$X$ variable 2 & $-6.8 E-05$ & $2.46 E-05$ & -2.75481 & 0.0092 & -0.0001 & $-1.8 E-05$ \\
\hline
\end{tabular}



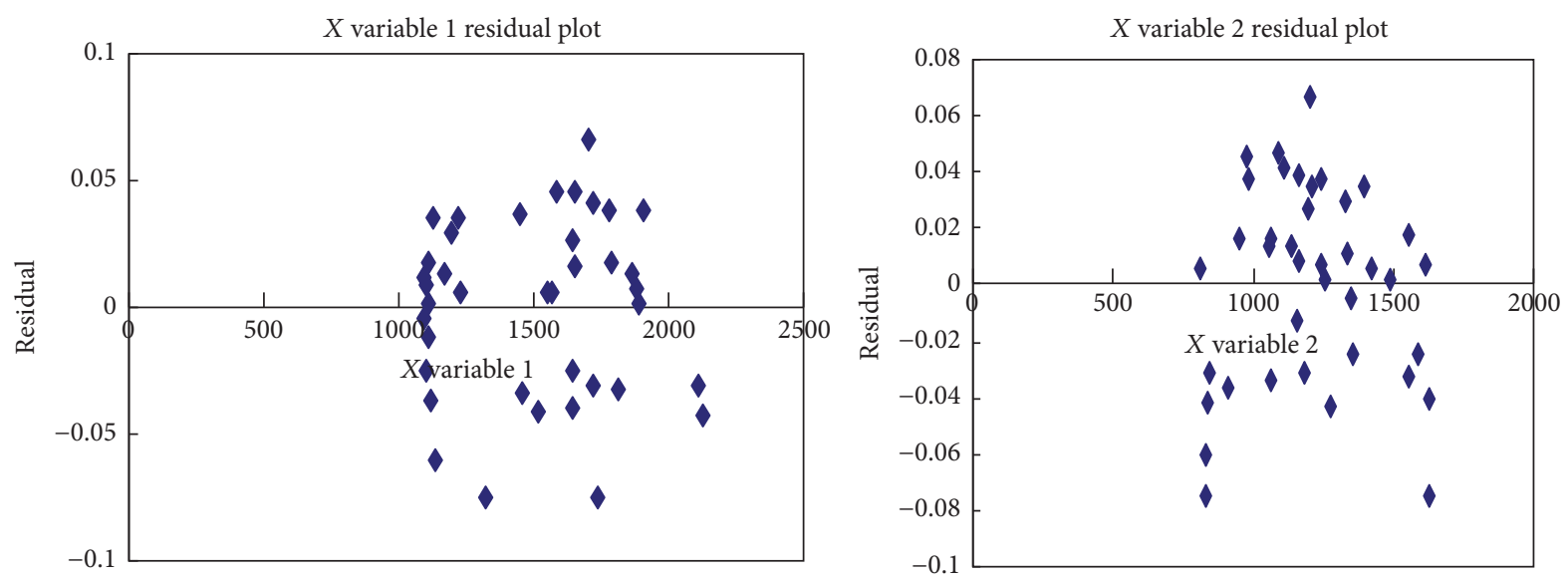

FIGURE 4: Residual analysis.

plot distribute on both side of $x$ axis and the residual value is located between -2 and 2 present that the regression equation can better reflect the rules. For other models, testing results also demonstrate the effectiveness of proposed method.

In the following section, the results of the proposed prediction models are compared with the models proposed by Morris and Donnell [29] and the speed models recommended in Guidelines for Safety Audit of Highway (GSAH) (JTG/T B05-2004) [47] which is the only national profession standard for operating speed prediction and alignment consistency evaluation in China. Three common criteria are used to evaluate the prediction performance of different models: mean absolute error (MAE), root mean square error (RMSE), and mean absolute relative error (MARE). Moreover, the standard deviation (SD) is also used as the evaluation indicator. The four indicators are defined in (17), (18), (19), and (20):

$$
\begin{aligned}
\text { MAE } & =\frac{1}{n} \sum_{i=1}^{n}\left|t_{i}-\widehat{t}_{i}\right|, \\
\operatorname{RMSE} & =\sqrt{\frac{1}{n} \sum_{i=1}^{n}\left(t_{i}-\widehat{t_{i}}\right)^{2},} \\
\operatorname{MARE}(\%) & =\frac{1}{n} \sum_{i=1}^{n} \frac{\left|t_{i}-\widehat{t}_{i}\right|}{t_{i}} \times 100, \\
\mathrm{SD} & =\sqrt{\frac{1}{n} \sum_{i=1}^{n}\left(\widehat{t}_{i}-\overline{t_{i}}\right)^{2},}
\end{aligned}
$$

where $n$ is the number of testing points, $t_{i}$ and $\overline{t_{i}}$ denote the actual observed values and mean values of operating speed, respectively, and $\widehat{t}_{i}$ represents the predicting values of operating speed.

To consider different position of operating speed according to the GSAH model and proposed models in this paper, we finally compare the prediction results of three models at 480 points on $3 \mathrm{D}$ alignment with length of $12 \mathrm{~km}$. From Table 4, it is indicated that the estimation errors for other two models which are calculated by using (17) through (20) are generally higher than those for the proposed models. Some comparison results of actual test speed data and prediction data are shown in Figure 5. Thus, the prediction models introduced in this study obviously outperform the GSAH models and Morris's models for its higher accuracy.

With respect to the consideration of vehicle dynamic properties into the model, operating speed on a current section is the result of cumulative speed change of the reartraveled sections. The speed differences existing between the front and rear sections are induced by the acceleration and deceleration of a vehicle. Thus, the influence range of rear alignment can be approximately characterized by the acceleration and deceleration distance which is related to vehicle dynamic properties. Based on each vehicle trajectory and recommended deceleration rate, the influence range of the rear alignment can be determined as $200 \mathrm{~m}$.

The related researches on how to quantify driver's visual information to a digital index are lacking. The deceleration rate of vehicles in China has significant differences from that in worldwide. At the same time, the influence range of rear alignment is also determined based on data analysis. Thus, we did not discuss more about these two considerations. In the case study, the other two models did not consider the influence of visual characteristics and vehicle dynamics; they just establish the relation between operating speed and alignment indexes. We think that the comparison results may reflect the accuracy of our model with these considerations.

\section{Conclusions}

One significant limitation in previous research work on highway alignment design consistency is that the existing operating speed prediction models are established mainly on 2D alignment or single index. Particularly when the road is characterized by different alignment combinations, the models may be inaccurate. Only some feature points, such as the middle point of a horizontal curve or the end point of a grade can be predicted correspondingly. Therefore, the 
TABLE 4: Comparison results of three models.

\begin{tabular}{|c|c|c|c|c|}
\hline \multirow{2}{*}{ Vehicle type } & \multirow{2}{*}{ Criteria } & \multicolumn{3}{|c|}{ Estimation methods } \\
\hline & & Proposed model & GSAH & Morris \\
\hline \multirow{4}{*}{ Cars } & MAE & 2.69 & 4.45 & 10.29 \\
\hline & RMSE & 3.54 & 6.03 & 13.67 \\
\hline & MARE (\%) & 4.38 & 6.98 & 10.28 \\
\hline & SD & 10.7 & 15.32 & 18.21 \\
\hline \multirow{4}{*}{ Trucks } & MAE & 3.57 & 6.89 & 16.32 \\
\hline & RMSE & 7.10 & 10.22 & 21.04 \\
\hline & MARE (\%) & 4.93 & 6.34 & 15.39 \\
\hline & SD & 8.85 & 14.17 & 17.33 \\
\hline
\end{tabular}

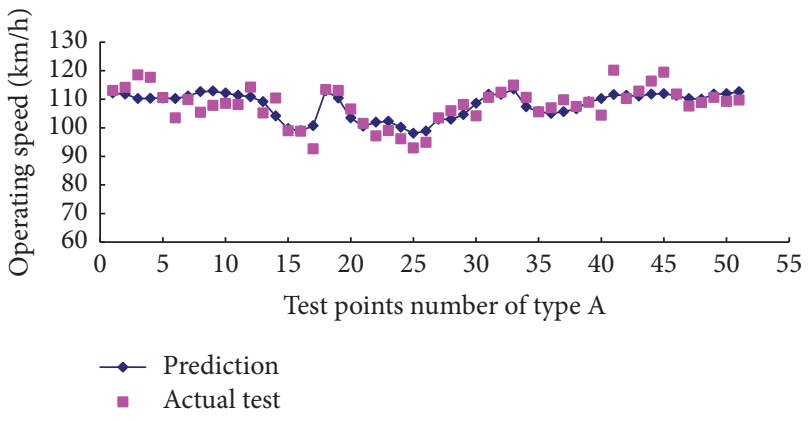

(a)

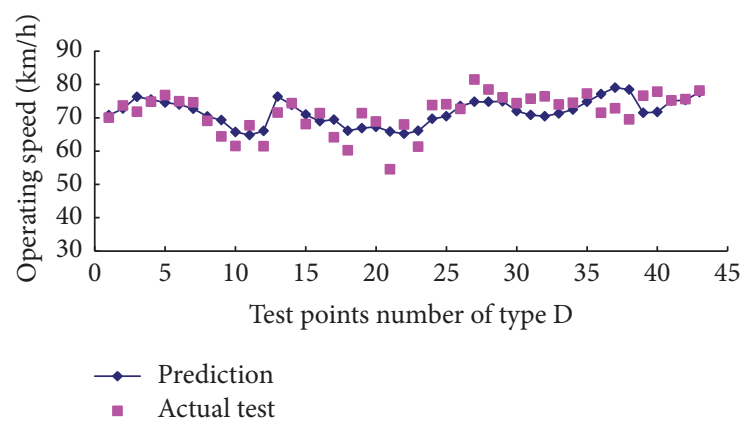

(b)

FIGURE 5: Comparison between predicted speed and actual speed. (a) Comparison for cars. (b) Comparison for trucks.

speed variation of passenger cars and trucks along each point of the road is studied using the actual test data and alignment indices.

The achievements of this study are twofold. The first one is the three-dimensional alignment comprehensive index description functions. These functions select curvature, change rate of curvature, curve angle, grade, and lane width as variables rather than a single index. Based on the principle of spatial geometry and the design characteristics of road alignment, the alignment description model is established by taking the horizontal and vertical indices as the primary models and the cross-sectional index as the correction model. The second process is to set up the relationship between alignment comprehensive index and operating speed for continuous prediction. During the establishment of this model, the visual requirement of driver and the different features of acceleration and deceleration of vehicles are also considered. This modeling procedure makes it possible to predict a reliable and continuous operating speed profile at each point along the alignment and to significantly improve the performance of consistency alignment design and safety evaluations. The prediction performance of the proposed model demonstrates its higher accuracy when compared with other models using the actual observed data.

Owing to the test data mainly collected on highways (bidirectional four to eight lanes) in plain area in China, the models reported in the paper can be used to predict continuous operating speed for passenger cars and trucks on the condition of three-dimensional alignment indexes along roadway which can be obtained. However, the models cannot predict the operating speeds in mountainous area or other type roads accurately. Application of the model outside China would require a new calibration based on local speed surveys because of the differences in driver behavior, roadway systems, and vehicle performances. Although design speed and speed limit have effect on operating speed to some extent, these factors are not considered in models. Substantially, highway alignment is a three-dimensional curve in Euclidean space. The interaction mechanism of multiple alignment indices on speed is very complicated. Hence, the methods of alignment comprehensive modeling are required further study. With the development of automotive technology, fusion of data collected from mobile and fixed sensors [48], and the improvement of road conditions, results of the prediction model may deviate from the actual values; thus, the model can be further examined, updated, and improved. Future efforts should focus on these factors in order to explore more efficient models.

\section{Conflicts of Interest}

The authors declare that there are no conflicts of interest regarding the publication of this paper.

\section{Acknowledgments}

The project is supported by National Natural Science Foundation of China (51308059 and 71701215), China Postdoctoral 
Science Foundation (2015M581585), the Special Fund for Basic Scientific Research of Central Colleges, Chang'an University (310822152007), and Western Transportation Science and Technology Project of Ministry of Communications (2012318361110).

\section{References}

[1] F. Russo, S. A. Biancardo, and M. Busiello, "Operating speed as a key factor in studying the driver behaviour in a rural context," Transport, vol. 31, no. 2, pp. 260-270, 2016.

[2] G. Dell'acqua, M. Busiello, and F. Russo, "Safety data analysis to evaluate highway alignment consistency," Transportation Research Record, no. 2349, pp. 121-128, 2013.

[3] J. L. Ottesen and R. A. Krammes, "Speed-profile model for a design-consistency evaluation procedure in the United States," Transportation Research Record: Journal of the Transportation Research Board, no. 1701, pp. 76-85, 2000.

[4] N. J. Garber, "The effect of speed, flow, and geometric characteristics on crash rates for different types of Virginia highways," Virginia Transportation Research Council, vol. 1, pp. 10-15, 2000.

[5] German Road and Transportation Research Association, Guidelines for the Design of Roads, Berlin, 1984.

[6] J. Morrall and R. J. Talarico, "Side friction demanded and margins of safety on horizontal curves," Transportation Research Record: Journal of the Transportation Research Board, pp. 145152, 1994.

[7] Transportation of Ontario, Ontario Traffic Manual Book 7: Temporary Conditions, Ontario, 2014.

[8] Turner-Fairbank Highway Research Center.: Interactive Highway Safety Design Model, Federal Highway Administration, Mclean, 2003.

[9] R. Lamm, E. M. Choueiri, J. C. Hayward, and A. Paluri, "Possible design procedure to promote design consistency in highway geometric design on two-lane rural roads," Transportation Research Record, no. 1195, pp. 111-122, 1988.

[10] M. N. Islam and P. N. Seneviratne, "Evaluation of design consistency of two-lane rural highways," Journal of Transportation of the Institute of Transportation Engineers, vol. 64, no. 2, pp. 28-31, 1994.

[11] J. McFadden and L. Elefteriadou, "Evaluating horizontal alignment design consistency of two-lane rural highways: development of new procedure," Transportation Research Record, no. 1737, pp. 9-17, 2000.

[12] R. A. Krammes et al., HorizoNtal Alignment Design Consistency for Rural Two-Lane Highways, Federal Highway Administration, 1994.

[13] A. Bucchi, K. Biasuzzi, and A. Simone, "Evaluation of design consistency: a new operating speed model for rural roads on grades," Transportation Research Record: Journal of the Transportation Research Board, vol. 1701, pp. 76-85, 2005.

[14] J. Tang, F. Liu, Y. Zou, W. Zhang, and Y. Wang, "An Improved Fuzzy Neural Network for Traffic Speed Prediction Considering Periodic Characteristic," IEEE Transactions on Intelligent Transportation Systems, 2017.

[15] P. Perco, "Influence of the general character of horizontal alignment on operating speed of two-lane rural roads," Transportation Research Record, no. 2075, pp. 16-23, 2008.

[16] A. A. Abdul-Mawjoud and G. G. Sofia, "Development of models for predicting speed on horizontal curves for two-lane rural highways," Arabian Journal for Science and Engineering, vol. 33, no. 2 B, pp. 365-377, 2008.

[17] Y. Yan, S. Zhang, J. Tang, and X. Wang, "Understanding characteristics in multivariate traffic flow time series from complex network structure," Physica A: Statistical Mechanics and its Applications, vol. 477, pp. 149-160, 2017.

[18] K. Fitzpatrick, Design Speed, Operating Speed, and Posted Speed Practices, Transportation Research Board, 2003.

[19] D. R. Jessen, K. S. Schurr, P. T. McCoy, G. Pesti, and R. R. Huff, "Operating speed prediction on crest vertical curves of rural two-lane highways in Nebraska," Transportation Research Record: Journal of the Transportation Research Board, no. 1751, pp. 67-75, 2001.

[20] D. B. Fambro, K. Fitzpatrick, and C. W. Russell, "Operating speed on crest vertical curves with limited stopping sight distance," Transportation Research Record: Journal of the Transportation Research Board, no. 1701, pp. 25-31, 2000.

[21] G. M. Gibreel, S. M. Easa, and I. A. El-Dimeery, "Prediction of operating speed on three-dimensional highway alignments," Journal of Transportation Engineering, vol. 127, no. 1, pp. 21-30, 2001.

[22] E. M. Choueiri, R. Lamm, J. H. Kloeckner, and T. Mailaender, "Safety aspects of individual design elements and their interactions on two-lane highways: international perspective," Transportation Research Record, no. 1445, pp. 34-46, 1994.

[23] J. Tang, F. Liu, W. Zhang, R. Ke, and Y. Zou, "Lane-changes prediction based on adaptive fuzzy neural network," Expert Systems with Applications, vol. 91, pp. 452-463, 2018.

[24] H. Gong and N. Stamatiadis, "Operating speed prediction models for horizontal curves on rural four-lane highways," Transportation Research Record, no. 2075, pp. 1-7, 2008.

[25] X. H. Li and Z. K. Yao, "Vehicle fuel consumption prediction model," Journal of Tongji University, vol. 20, no. 4, pp. 403-410, 1992.

[26] A. Calvi and F. Bella, "Modeling speed differential parameters in day and night environments using driving simulator," in Proceedings of the 2014 9th International Symposium on Safety Science and Technology, ISSST 2014, pp. 648-661, China, November 2014.

[27] A. M. Semeida, "Application of artificial neural networks for operating speed prediction at horizontal curves: a case study in Egypt," Journal of Modern Transportation, vol. 22, no. 1, pp. 20-29, 2014.

[28] E. T. Donnell, Y. Ni, M. Adolini, and L. Elefteriadou, "Speed prediction models for trucks on two-lane rural highways," Transportation Research Record, no. 1751, pp. 44-55, 2001.

[29] C. M. Morris and E. T. Donnell, "Passenger car and truck operating speed models on multilane highways with combinations of horizontal curves and steep grades," Journal of Transportation Engineering, vol. 140, no. 11, Article ID 04014058, 2014.

[30] J. E. Leisch and J. P. Leisch, "New concepts in design-speed application," Transportation Research Record, no. 631, pp. 15-23, 1977.

[31] A. Montella, F. Galante, F. Mauriello, and M. Aria, "Continuous speed profiles to investigate srivers' behavior on two-lane rural highways," Transportation Research Record, vol. 2521, pp. 3-11, 2015.

[32] Transportation Research Board (TRB), Modeling operating speed. Synthesis report. Transportation Research Circular Number E-C151, Transportation Research Board, Washington, D.C., 2011. 
[33] A. M. P. Zuriaga, A. G. García, F. J. C. Torregrosa, and P. D'Attoma, "Modeling operating speed and deceleration on two-lane rural roads with global positioning system data," Transportation Research Record, no. 2171, pp. 11-20, 2010.

[34] F. Bella, A. Calvi, and P. D’Attoma, “Operating speed prediction for Italian two-lane rural roads using speed profiles from GPS data," in Proceedings of the 4th road safety and simulation international conference, Rome, 2013.

[35] S. Cafiso and G. Cerni, "New approach to defining continuous speed profile models for two-lane rural roads," Transportation Research Record, no. 2309, pp. 157-167, 2012.

[36] G. Reymond, A. Kemeny, J. Droulez, and A. Berthoz, "Role of lateral acceleration in curve driving: Driver model and experiments on a real vehicle and a driving simulator," Human Factors: The Journal of the Human Factors and Ergonomics Society, vol. 43, no. 3, pp. 483-495, 2001.

[37] D. W. Harwood, A. D. May, and I. B. Anderson, "Capacity and quality of service of two-Lane highways," Transportation Research Board of the National Academies, 1999.

[38] F. S. Mertzanis and V. J. Hatzi, "Model for sight distance calculation and three-dimensional alignment evaluation in divided and undivided highways," in Proceedings of the 3rd international conference on road safety and simulation, Indianapolis, 2011.

[39] T. Kim and H. Michael Zhang, "Interrelations of reaction time, driver sensitivity, and time headway in congested traffic," Transportation Research Record, no. 2249, pp. 52-61, 2011.

[40] TRB, Highway Capacity Manual, Transportation research board of the national academies, 2010.

[41] A. W. Inhoff, M. S. Solomon, B. A. Seymour, and R. Radach, "Eye position changes during reading fixations are spatially selective," Vision Research, vol. 48, no. 8, pp. 1027-1039, 2008.

[42] S. M. Easa and W. He, "Modeling driver visual demand on threedimensional highway alignments," Journal of Transportation Engineering, vol. 132, no. 5, pp. 357-365, 2006.

[43] "JTG B01-2014: Technical Standard of Highway Engineering, 2015".

[44] A. M. Pérez-Zuriaga, F. J. Camacho-Torregrosa, and A. García, "Tangent-to-curve transition on two-lane rural roads based on continuous speed profiles," Journal of Transportation Engineering, vol. 139, no. 11, pp. 1048-1057, 2013.

[45] K. Fitzpatrick, L. Elefteriadou, D. Harwood et al., Speed Prediction for Two-Lane Rural Highways, FHWA, U.S. Department of Transportation, 2000.

[46] Y. Yan and Z. Y. Guo, Alignment Consistency Evaluation Based on Operating Speed Prediction Models, Tongji University, Shanghai Shi, China, 2009.

[47] H. T. Zhou, C. H. Yang, Z. Y. Guo et al., Guidelines for Safety Audit of Highway, JTG/T B05-2004, Ministry of Communications of the People's Republic of China, China, 2004.

[48] S. Zhang, J. Tang, H. Wang, Y. Wang, and S. An, "Revealing intra-urban travel patterns and service ranges from taxi trajectories," Journal of Transport Geography, vol. 61, pp. 72-86, 2017. 


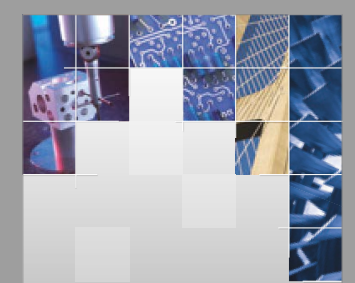

\section{Enfincering}
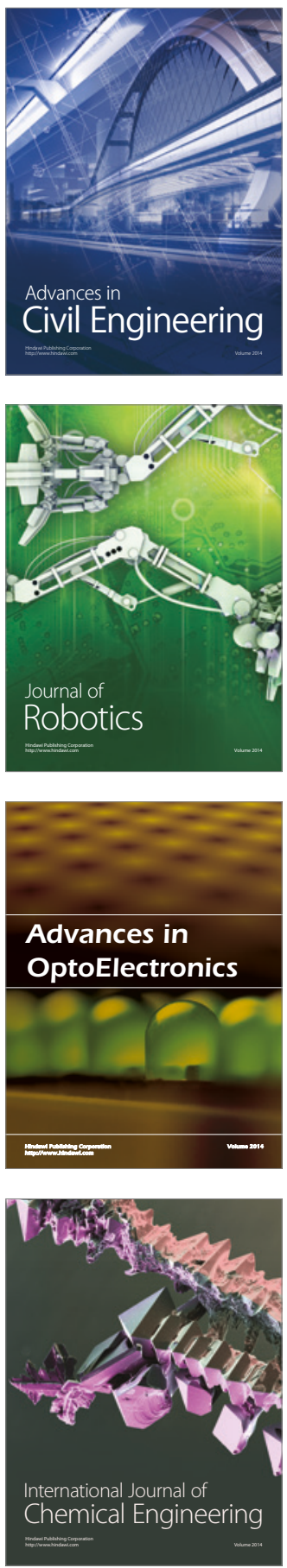

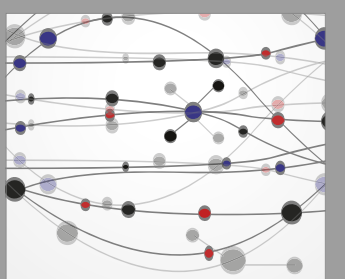

The Scientific World Journal

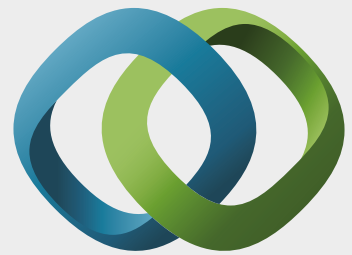

\section{Hindawi}

Submit your manuscripts at

https://www.hindawi.com
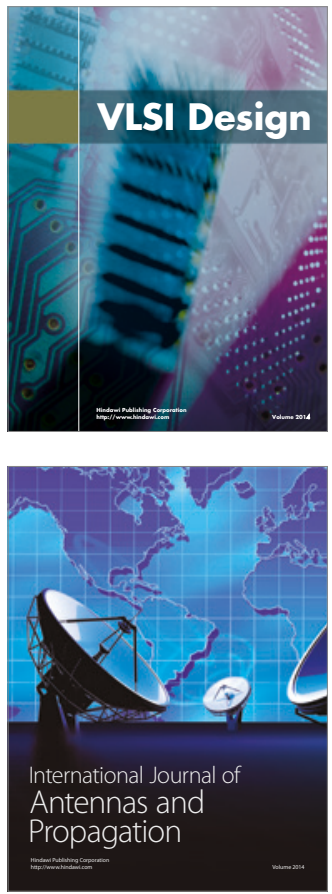

\section{Rotating}

Machinery
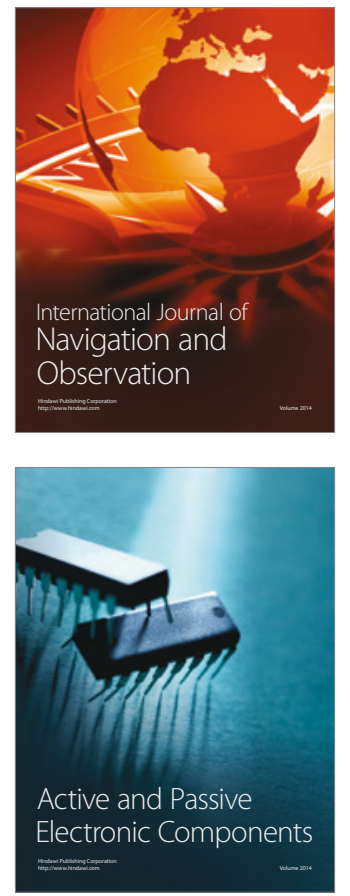
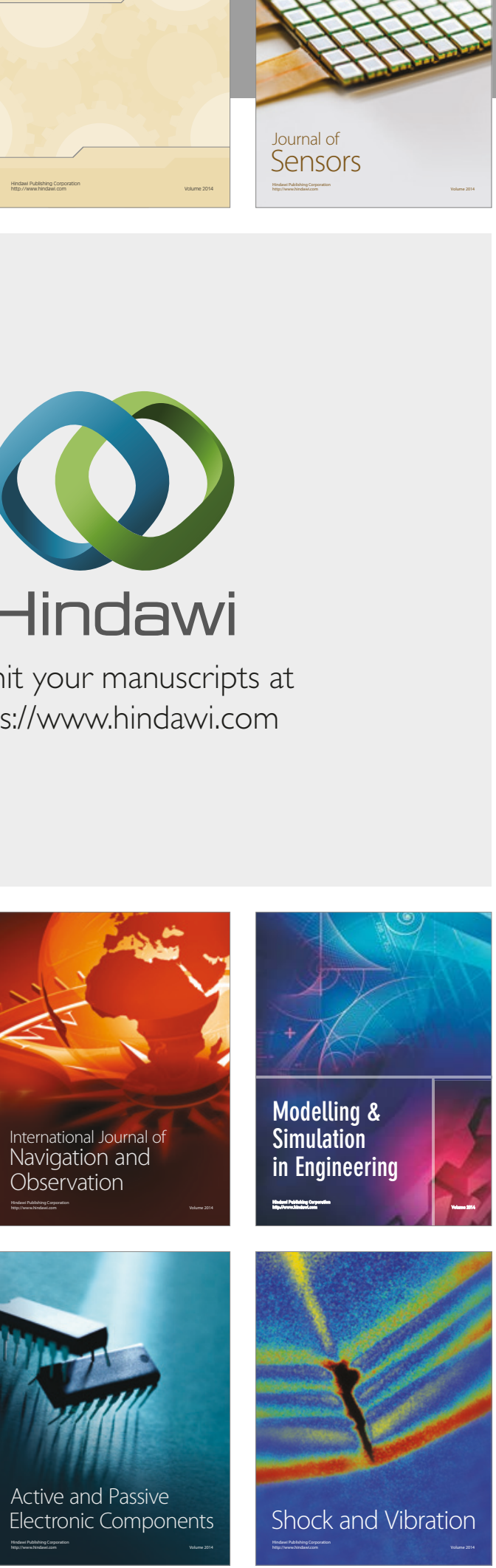
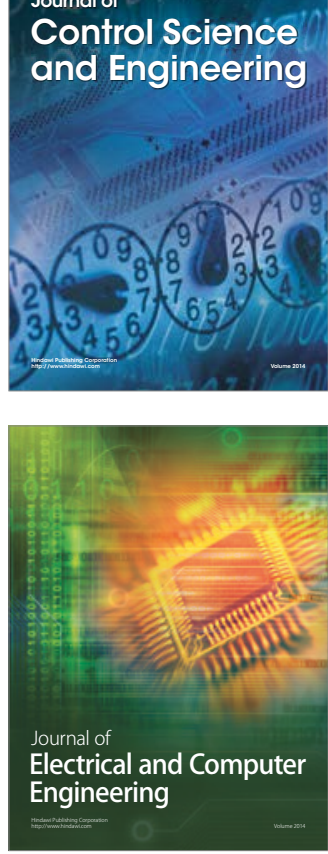

Distributed

Journal of

Control Science

and Engineering
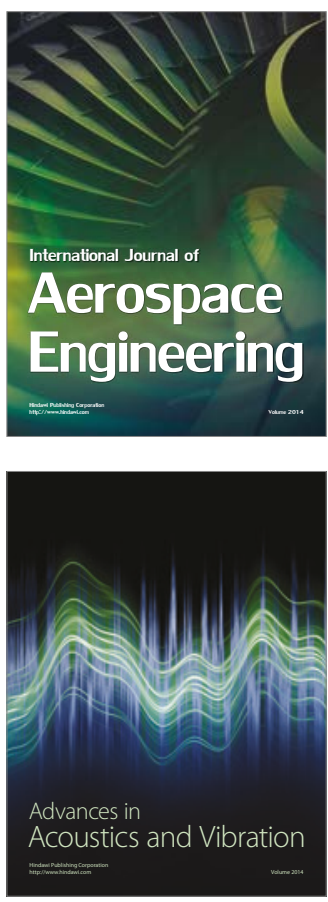

Sensor Networks 